Article

\title{
Interval-Valued Fuzzy Cooperative Games Based on the Least Square Excess and Its Application to the Profit Allocation of the Road Freight Coalition
}

\author{
Wen-Jian Zhao ${ }^{1}$ and Jia-Cai Liu ${ }^{2, *(1)}$ \\ 1 Jinshan College, Fujian Agriculture and Forestry University, Fuzhou 350002, China; \\ wenjianzhao@fafu.edu.cn \\ 2 College of Transportation and Civil Engineering, Fujian Agriculture and Forestry University, \\ Fuzhou 350002, China \\ * Correspondence: liujiacai@fafu.edu.cn; Tel.: +86-150-6004-2796
}

Received: 21 November 2018; Accepted: 29 November 2018; Published: 3 December 2018

\begin{abstract}
This paper is mainly committed to constructing a new model for solving interval-valued fuzzy cooperative games based on the least square excess. We propose the interval-valued least square excess solution according to the solution concept of the least square prenucleolus and the least square nucleolus for solving crisp cooperative games. In order to obtain the corresponding optimal analytical solution, one mathematic programming model is constructed. The least square excess solution can be used to determine plays' payoffs directly. Considering the fuzziness and uncertainty existing in the process of the road freight coalition, we establish the interval-valued fuzzy utility function of the road freight coalition that can properly reflect the real situation in view of the green logistics. The illustratively calculated results show that the least square excess solution proposed in this paper is effectual and ascendant, and satisfied many important and useful properties of cooperative games, such as symmetry and uniqueness. As for the problems of interval-valued cooperative games, the model proposed in this paper can be applied appropriately to obtain the players' interval-valued payoffs.
\end{abstract}

Keywords: fuzzy game; cooperative game; interval; road freight coalition; green logistics

\section{Introduction}

There are many fuzzy and uncertain phenomenon or things in the activities of daily life. Many classical cooperative game theories and methods have been extended to the fuzzy field in recent years. Many kinds of fuzzy numbers are used to express the fuzziness and uncertainty, one of which is the interval. Intervals use the upper bound and the lower bound to represent a possible range of values. Unlike triangular/trapezoidal fuzzy numbers or intuitionistic triangular/trapezoidal fuzzy numbers, the membership of each possible value is equal to 1 for the intervals, which can effectively reduce the amplification of fuzziness during the process of calculation. The fuzzy cooperative games with coalition values expressed as intervals are usually called the interval-valued cooperative games [1-3].

In recent years, the theory on interval-valued cooperative games has already been studied more and more deeply. At the same time, their theory is applied to many fields, such as green logistics, supply chain management, and ecological construction [4-6]. One vivid and classical application example of the interval-valued cooperative games is the bankruptcy model [7]. Branzei et al. [7] proposed two values that looked like the Shapley value, and analyzed their relationships according to the interval arithmetic [8]. In order to apply the interval-valued cooperative game theory more extensively so as to solve practical problems and constantly enhance researchers' interest in interval-valued 
cooperative games, Branzei et al. [1] reviewed the existing interval-valued cooperative game theory and prospected its potential application in many fields, such as economy and management. Alparslan [2] analysed the properties of one kind of interval-valued Shapley value and showed its axiomatic characterization. Kimms et al. [9] proposed one kind of mathematical programming method, which was used to determine the interval-valued core. Alparslan et al. [10] generalized several kinds of interval-valued cooperative game's set-value solutions, such as interval stable sets and the interval Shapley value. Branzei et al. [11] proposed the interval core of the interval-valued cooperative games. Alparslan et al. [12] developed the classical two-person cooperative game theory and proposed the solution concepts and methods of the interval-valued two-person cooperative game. However, many of the solutions of the fuzzy cooperative games mentioned above inevitably used the arithmetic operations of fuzzy numbers, especially the subtraction operation of fuzzy numbers. As is known to all, the subtraction operation of the fuzzy numbers could directly result in the distortion of information and in the amplification of fuzziness. In order to solve the income distribution or cost sharing problems of fuzzy cooperative games more effectively, we propose the interval-valued least square excess solution of interval-valued cooperative games.

The remainder of this paper unfolds as follows. Section 2 introduces some important preliminaries, such as the square distance between intervals and the concept of the square excess. Section 3 introduces the concept of the interval-valued least square excess solution of interval-valued cooperative games. Section 4 gives the solving process of the interval-valued least square excess solution through constructing the corresponding Lagrange function. In Section 5, the cost accounting method of the road freight is studied, the computational formula is given, and the utility function is constructed. Furthermore, the interval-valued least square excess solution is illustrated with a real practical example about profit allocation in the road freight coalition, and is compared with the interval Shapley-like value. In Section 6, some advantages of the proposed interval-valued least square excess solution are discussed, and the future research focus and direction are prospected.

\section{Preliminaries}

In this section, we will introduce some corresponding concepts, theories, and terms, such as intervals, square excess, and fuzzy cooperative games.

\subsection{Intervals and the Square Distance between Intervals}

Considering the following interval, shown as $\bar{a}=\left[a_{L}, a_{R}\right]=\left\{x \mid x \in R, a_{L} \leq x \leq a_{R}\right\}$, where $a_{L} \in \mathrm{R}, a_{R} \in \mathrm{R}$. $\mathrm{R}$ is called the real number set. It is easy to find that the interval $\bar{a}=\left[a_{L}, a_{R}\right]$ degenerates to a real number when $a_{L}=a_{R}$. In other words, intervals are one type of real numbers' generalization, or the real number are a special case of the interval.

For the sake of the clear description of the square excess, the square distance between intervals $\bar{a}$ and $\bar{b}$ can be given as $D(\bar{a}, \bar{b})=\left(a_{L}-b_{L}\right)^{2}+\left(a_{R}-b_{R}\right)^{2}$.

\subsection{Some Concept and Definition of Fuzzy Cooperative Games}

For any interval-valued cooperative game $\bar{v} \in \bar{G}^{n}$, as the coalition values are expressed by intervals, it can be inferred that the players' payoff distributed from the coalition should also be intervals. Let $\bar{x}_{i}=\left[x_{L i}, x_{R i}\right](i \in N)$ represent the interval-valued payoff distributed from the largest coalition, $N$. Therefore, $\bar{x}=\left(\bar{x}_{1}, \bar{x}_{2}, \cdots, \bar{x}_{n}\right)^{\mathrm{T}}$ is shown as the interval-valued payoff vector distributed from the largest coalition, $N$. For any coalition, $S \subseteq N$ denotes $\bar{x}(S)=\sum_{i \in S} \bar{x}_{i}$, which means the sum of the players' interval-valued payoffs who take part in the coalition, $S$. According to the interval arithmetic $[8,13,14], \bar{x}(S)$ is also an interval, as follow: $\bar{x}(S)=\left[x_{L}(S), x_{R}(S)\right]=\left[\sum_{i \in S} x_{L i}, \sum_{i \in S} x_{R i}\right]$. 


\subsection{The Concept of the Square Excess}

Similar to the efficiency condition of the classical cooperative game, for an interval-valued cooperative game, $\bar{v} \in \bar{G}^{n}$, if $\bar{x}=\left(\bar{x}_{1}, \bar{x}_{2}, \cdots, \bar{x}_{n}\right)^{\mathrm{T}}$ satisfies the efficiency as follows: $\sum_{i=1}^{n} \bar{x}_{i}=\bar{v}(N)$, then the vector $\bar{x}$ is called a preimputation of interval-valued cooperative game $\bar{v} \in \bar{G}^{n}$. That is to say, as long as $\bar{x}(N)=\bar{v}(N)$, the interval-valued payoff vector $\bar{x}$ can be treated as one pre-imputation. $\bar{I}^{\mathrm{Pr}}(\bar{v})$ denotes the set of interval-valued preimputations of an interval-valued cooperative game $\bar{v} \in \bar{G}^{n}$.

Based on Moore's interval order relation [8], the interval-valued cooperative game's efficiency condition can be expressed as follows:

$$
\left\{\begin{array}{l}
\sum_{i=1}^{n} x_{L i}=v_{L}(N) \\
\sum_{i=1}^{n} x_{R i}=v_{R}(N) .
\end{array}\right.
$$

For any $\bar{x}$ and $S(S \neq \varnothing)$, denote

$$
e(S, \bar{x})=\left(v_{L}(S)-x_{L}(S)\right)^{2}+\left(v_{R}(S)-x_{R}(S)\right)^{2},
$$

which is expressed as the square excess of $S$ on $\bar{x}$. Generally, for any $S(S \subseteq N),\left(v_{L}(S)-x_{L}(S)\right)$ is denoted by $e_{L}(S, \bar{x})$ and $\left(v_{R}(S)-x_{R}(S)\right)$ is denoted by $e_{R}(S, \bar{x})$, that is,

$$
e_{L}(S, \bar{x})=\left(v_{L}(S)-x_{L}(S)\right)
$$

and

$$
e_{R}(S, \bar{x})=\left(v_{R}(S)-x_{R}(S)\right)
$$

respectively. $e_{L}(S, \bar{x})$ is called the lower bound of $e(S, \bar{x})$ and $e_{R}(S, \bar{x})$ is called the upper bound of $e(S, \bar{x})$. Then, $e(S, \bar{x})$ can be rewritten as follows:

$$
e(S, \bar{x})=\left(e_{L}(S, \bar{x})\right)^{2}+\left(e_{R}(S, \bar{x})\right)^{2}
$$

$e(S, \bar{x})$ can be used to measure the coalitions' dissatisfaction degrees. It is easy to see that the greater $e(S, \bar{x})$, the more unfair $S$ would feel.

\section{The Interval-Valued Least Square Excess Solution of Interval-Valued Cooperative Games}

Similar to the prenucleolus $[15,16]$ of classical cooperative games, the interval-valued least square excess solution is a one kind of solution concept on the basis of the square excess. The key to obtaining the interval-valued least square excess solution is to minimize the maximal dissatisfaction degrees. This idea sounds reasonable and effective. However, instead of adjusting relatively greater payoffs, according to the target that $\sum_{S \subseteq N} e(S, \bar{x})$ gets minimum, we try to select the interval-valued payoff vector that minimizes the coalitions' sum of the differences of the square excesses to balance each player's allocation. Next, we mainly consider the quadratic programming model, as follows:

$$
\begin{aligned}
& \min \left\{\sum_{S \subseteq N, S \neq \varnothing}\left[\left(e_{L}(S, \bar{x})-\bar{e}_{L}(S, \bar{x})\right)^{2}+\left(e_{R}(S, \bar{x})-\bar{e}_{R}(S, \bar{x})\right)^{2}\right]\right\} \\
& \text { s.t. }\left\{\begin{array}{l}
\sum_{i=1}^{n} x_{L i}=v_{L}(N) \\
\sum_{i=1}^{n} x_{R i}=v_{R}(N),
\end{array}\right.
\end{aligned}
$$


where $\bar{e}_{L}(S, \bar{x})$ and $\bar{e}_{R}(S, \bar{x})$ are the average excesses at $\bar{x}$, given by

$$
\bar{e}_{L}(S, \bar{x})=\frac{1}{2^{n-1}} \sum_{S \subseteq N, S \neq \varnothing} e_{L}(S, \bar{x})
$$

and

$$
\bar{e}_{R}(S, \bar{x})=\frac{1}{2^{n-1}} \sum_{S \subseteq N, S \neq \varnothing} e_{R}(S, \bar{x}),
$$

respectively.

The conclusion can be easily drawn that

$$
\begin{aligned}
& \sum_{S \subseteq N, S \neq \varnothing} e_{L}(S, \bar{x})=\sum_{S \subseteq N, S \neq \varnothing}\left(v_{L}(S)-x_{L}(S)\right) \\
= & \sum_{S \subseteq N, S \neq \varnothing} v_{L}(S)-\sum_{S \subseteq N, S \neq \varnothing} x_{L}(S)=\sum_{S \subseteq N, S \neq \varnothing} v_{L}(S)-\frac{1}{2}\left[\sum_{S \subseteq N, S \neq \varnothing} x_{L}(S)+\sum_{S \subseteq N, S \neq \varnothing} x_{L}(N \backslash S)+x_{L}(N)\right] \\
= & \sum_{S \subseteq N, S \neq \varnothing} v_{L}(S)-\frac{1}{2} \sum_{S \subseteq N, S \neq \varnothing}^{\sum}\left(x_{L}(S)+x_{L}(N \backslash S)\right)-\frac{1}{2} x_{L}(N)=\sum_{S \subseteq N, S \neq \varnothing} v_{L}(S)-\frac{1}{2}\left(2^{n}-1\right) x_{L}(N)-\frac{1}{2} x_{L}(N) \\
= & \sum_{S \subseteq N, S \neq \varnothing} v_{L}(S)-2^{n-1} x_{L}(N)=\sum_{S \subseteq N, S \neq \varnothing} v_{L}(S)-2^{n-1} v_{L}(N),
\end{aligned}
$$

that is,

$$
\sum_{S \subseteq N, S \neq \varnothing} e_{L}(S, \bar{x})=\sum_{S \subseteq N, S \neq \varnothing} v_{L}(S)-2^{n-1} v_{L}(N) .
$$

Similarly, we can prove that

$$
\sum_{S \subseteq N, S \neq \varnothing} e_{R}(S, \bar{x})=\sum_{S \subseteq N, S \neq \varnothing} v_{R}(S)-2^{n-1} v_{R}(N) .
$$

According to Equations (2), (3), (7), and (8), and combining with the arithmetic operations of intervals $[8,13,14]$, Equation (4) can be rewritten as follows:

$$
\begin{aligned}
& \min \left\{\sum_{S \subseteq N, S \neq \varnothing}\left[v_{L}(S)-x_{L}(S)-\frac{1}{2^{n}-1}\left(\sum_{S \subseteq N, S \neq \varnothing} v_{L}(S)-2^{n-1} v_{L}(N)\right)\right]^{2}\right. \\
& \left.+\sum_{S \subseteq N, S \neq \varnothing}\left[v_{R}(S)-x_{R}(S)-\frac{1}{2^{n}-1}\left(\sum_{S \subseteq N, S \neq \varnothing} v_{R}(S)-2^{n-1} v_{R}(N)\right)\right]^{2}\right\} \\
& \text { s.t. }\left\{\begin{array}{l}
\sum_{i=1}^{n} x_{L i}=v_{L}(N) \\
\sum_{i=1}^{n} x_{R i}=v_{R}(N) .
\end{array}\right.
\end{aligned}
$$

\section{The Solving Process of the Interval-Valued Least Square Excess Solution}

In this section, on the basis of the square excess, we focus on developing one kind of mathematical programming model for solving interval-valued cooperative games. Obviously, we can obtain the interval-valued least square excess solution through solving the mathematical programming model of Equation (9).

Equation (9) can be rewritten in the form of the Lagrange function, as follows:

$$
\begin{aligned}
L(\bar{x}, \lambda, \mu)= & \sum_{S \subseteq N, S \neq \varnothing}\left[v_{L}(S)-x_{L}(S)-\frac{1}{2^{n}-1}\left(\sum_{S \subseteq N, S \neq \varnothing} v_{L}(S)-2^{n-1} v_{L}(N)\right)\right]^{2} \\
& +\sum_{S \subseteq N, S \neq \varnothing}\left[v_{R}(S)-x_{R}(S)-\frac{1}{2^{n}-1}\left(\sum_{S \subseteq N, S \neq \varnothing} v_{R}(S)-2^{n-1} v_{R}(N)\right)\right]^{2} \\
& +\lambda\left(\sum_{i=1}^{n} x_{L i}-v_{L}(N)\right)+\mu\left(\sum_{i=1}^{n} x_{R i}-v_{R}(N)\right) .
\end{aligned}
$$

Next, we discuss how to solve the interval-valued optimal solution $\bar{x}^{*}=\left(\bar{x}_{1}^{*}, \bar{x}_{2}^{*}, \cdots, \bar{x}_{n}^{*}\right)^{\mathrm{T}}$ of Equation (9). 
The partial derivatives of $L(\bar{x}, \lambda, \mu)$ with regard to the variables $x_{L j}, x_{R j}(j \in S \subseteq N), \lambda$ and $\mu$ are obtained as follows:

$$
\begin{gathered}
\frac{\partial L(\bar{x}, \lambda, \mu)}{\partial x_{L j}}=-2 \sum_{S: i \in S}\left[v_{L}(S)-x_{L}(S)-\frac{1}{2^{n}-1}\left(\sum_{S \subseteq N, S \neq \varnothing} v_{L}(S)-2^{n-1} v_{L}(N)\right)\right]+\lambda, \\
\frac{\partial L(\bar{x}, \lambda, \mu)}{\partial \lambda}=\sum_{i=1}^{n} x_{L i}-v_{L}(N), \\
\frac{\partial L(\bar{x}, \lambda, \mu)}{\partial x_{R j}}=-2 \sum_{S: i \in S}\left[v_{R}(S)-x_{R}(S)-\frac{1}{2^{n}-1}\left(\sum_{S \subseteq N, S \neq \varnothing} v_{R}(S)-2^{n-1} v_{R}(N)\right)\right]+\mu
\end{gathered}
$$

and

$$
\frac{\partial L(\bar{x}, \lambda, \mu)}{\partial \mu}=\sum_{i=1}^{n} x_{R i}-v_{R}(N)
$$

respectively.

Let $\frac{\partial L(\bar{x}, \lambda, \mu)}{\partial x_{L j}}, \frac{\partial L(\bar{x}, \lambda, \mu)}{\partial \lambda}, \frac{\partial L(\bar{x}, \lambda, \mu)}{\partial x_{R j}}$ and $\frac{\partial L(\bar{x}, \lambda, \mu)}{\partial \mu}$ be equal to 0 , respectively, that is,

$$
\begin{gathered}
-2 \sum_{S: i \in S}\left[v_{L}(S)-x_{L}^{*}(S)-\frac{1}{2^{n}-1}\left(\sum_{S \subseteq N, S \neq \varnothing} v_{L}(S)-2^{n-1} v_{L}(N)\right)\right]+\lambda^{*}=0, \\
\sum_{i=1}^{n} x_{L i}^{*}=v_{L}(N), \\
-2 \sum_{S: i \in S}\left[v_{R}(S)-x_{R}^{*}(S)-\frac{1}{2^{n}-1}\left(\sum_{S \subseteq N, S \neq \varnothing} v_{R}(S)-2^{n-1} v_{R}(N)\right)\right]+\mu^{*}=0,
\end{gathered}
$$

and

$$
\sum_{i=1}^{n} x_{R i}^{*}=v_{R}(N)
$$

respectively.

It is obvious that

$$
\sum_{S: i \in S} x_{L}^{*}(S)=2^{n-1} x_{L i}^{*}+\sum_{j \in N \backslash i} 2^{n-2} x_{L j}^{*}(i, j \in N) .
$$

It can be easily derived from Equations (10) and (14) that

$$
-2 \sum_{S: i \in S} v_{L}(S)+2 \times 2^{n-1} x_{L i}^{*}+2 \times \sum_{j \in N \backslash i} 2^{n-2} x_{L j}^{*}+\frac{2}{2^{n}-1} \sum_{S \subseteq N, S \neq \varnothing} v_{L}(S)-\frac{2^{n}}{2^{n}-1} v_{L}(N)+\lambda^{*}=0
$$

According to the following equation

$$
x_{L i}^{*}+\sum_{j \in N \backslash i} x_{L j}^{*}=v_{L}(N)(i, j \in N),
$$

we can easily obtain

$$
-2 \sum_{S: i \in S} v_{L}(S)+2^{n-1} x_{L i}^{*}+\left(2^{n-1}-\frac{2^{n}}{2^{n}-1}\right) v_{L}(N)+\frac{2}{2^{n}-1} \sum_{S \subseteq N, S \neq \varnothing} v_{L}(S)+\lambda^{*}=0
$$

To solve $x_{L i}^{*}(i=1,2, \cdots, n)$, Equation (15) can be rewritten as follows:

$$
x_{L i}^{*}=\frac{2 \sum_{S: i \in S} v_{L}(S)-\left(2^{n-1}-\frac{2^{n}}{2^{n}-1}\right) v_{L}(N)-\frac{2}{2^{n}-1} \sum_{S \subseteq N, S \neq \varnothing} v_{L}(S)-\lambda^{*}}{2^{n-1}} .
$$


Then, the key to solve $x_{L i}^{*}$ becomes obtaining $\lambda^{*}$. It is easily derived from Equation (11), that

$$
\sum_{i \in N} \frac{2 \sum_{S: i \in S} v_{L}(S)-\left(2^{n-1}-\frac{2^{n}}{2^{n}-1}\right) v_{L}(N)-\frac{2}{2^{n}-1} \sum_{S \subseteq N, S \neq \varnothing} v_{L}(S)-\lambda^{*}}{2^{n-1}}=v_{L}(N),
$$

that is,

$$
2 \sum_{S \subseteq N, S \neq \varnothing} S v_{L}(S)-n\left(2^{n-1}-\frac{2^{n}}{2^{n}-1}\right) v_{L}(N)-\frac{2 n}{2^{n}-1} \sum_{S \subseteq N, S \neq \varnothing} v_{L}(S)-n \lambda^{*}=2^{n-1} v_{L}(N),
$$

where $s$ denotes the cardinality of coalitions $S \subseteq N$.

It is obvious that

$$
\lambda^{*}=\frac{2 \sum_{S \subseteq N, S \neq \varnothing} s v(S)}{n}-\left(2^{n-1}-\frac{2^{n}}{2^{n}-1}\right) v_{L}(N)-\frac{2}{2^{n}-1} \sum_{S \subseteq N, S \neq \varnothing} v_{L}(S)-\frac{2^{n-1}}{n} v_{L}(N) .
$$

It is derived from Equations (16) and (17), that

$$
\begin{aligned}
& x_{L i}^{*}=\frac{2 \sum_{S: i \in S} v_{L}(S)-\left(2^{n-1}-\frac{2^{n}}{2^{n}-1}\right) v_{L}(N)-\frac{2}{2^{n}-1} \sum_{S \subseteq N, S \neq \varnothing} v_{L}(S)}{2 \sum s v(S)} \\
& -\frac{\frac{\sum_{S \subseteq N, S \neq \varnothing}^{n} s v(S)}{n}-\left(2^{n-1}-\frac{2^{n}}{2^{n}-1}\right) v_{L}(N)-\frac{2}{2^{n}-1} \sum_{S \subseteq N, S \neq \varnothing} v_{L}(S)-\frac{2^{n-1}}{n} v_{L}(N)}{2 \sum_{S v_{L}^{n-1}}} \\
& =\frac{v_{L}(N)}{n}+\frac{2 \sum_{S: i \in S} v_{L}(S)-\frac{2 \sum_{S \subseteq N, S \neq \varnothing} v_{L}(S)}{n}}{2^{n-1}}=\frac{v_{L}(N)}{n}+\frac{1}{n 2^{n-2}}\left(n \sum_{S: i \in S} v_{L}(S)-\sum_{S \subseteq N, S \neq \varnothing} s v_{L}(S)\right) \\
& =\frac{v_{L}(N)}{n}+\frac{1}{n 2^{n-2}}\left(n a_{L i}(v)-\sum_{j \in N} \sum_{S: j \in S} v_{L}(S)\right)=\frac{v_{L}(N)}{n}+\frac{1}{n 2^{n-2}}\left(n a_{L i}(v)-\sum_{j \in N} a_{L j}(v)\right) \text {, }
\end{aligned}
$$

that is,

$$
x_{L i}^{*}=\frac{v_{L}(N)}{n}+\frac{1}{n 2^{n-2}}\left(n a_{L i}(v)-\sum_{j \in N} a_{L j}(v)\right)(i \in N),
$$

where $a_{L i}(v)=\sum_{S: i \in S} v_{L}(S)$.

Similarly, we can obtain the upper bounds of the interval-valued optimal solution $\bar{x}^{* \mathrm{E}}$ as follows:

$$
x_{R i}^{*}=\frac{v_{R}(N)}{n}+\frac{1}{n 2^{n-2}}\left(n a_{R i}(v)-\sum_{j \in N} a_{R j}(v)\right)(i \in N),
$$

where $a_{R i}(v)=\sum_{S: i \in S} v_{R}(S)$.

So far, we obtain the interval-valued optimal solution of Equation (9), which consists of Equations (18) and (19). Thus, if only the efficiency is considered, the interval-valued least square excess solution can be obtained as $\bar{x}_{i}^{*}=\left[x_{L i}^{*}, x_{R i}^{*}\right](i \in N)$, whose lower bounds and upper bounds are given by Equations (18) and (19), respectively.

\section{Profit Allocation Strategy of the Road Freight Coalition Based on the Interval-Valued Least Square Excess Solution}

The interval-valued cooperative game theory and method can be easily applied to many real fields, such as environment, finance, management, business, logistics, and supply chain. Next, we take the profit allocation of the road freight coalition as an example.

In the road freight industry, the solitary activity of logistics enterprises usually results in a tremendous waste of resources, and inevitably brings about serious environment pollution and 
damage. The theory and practice of the green logistics that can make logistics greener and more sustainable is imperative. As an effective measure of green logistics, the road freight coalition can effectively integrate resources and reduce energy consumption. In the following section, we will consider a road freight coalition composed of three logistics enterprises, which are named 1,2, and 3, separately. What needs to be explained in advance is that some data are taken from the process of the production operations of some logistics enterprises in Fujian province of China, and others are taken from the bidding and tendering agreement of those logistics enterprises mentioned above.

\subsection{Cost Accounting of the Road Freight and the Utility Function}

For the sake of the calculation of coalitions' utility function, some variables are described in Table 1 . The industry reference values and computational formulas are obtained from the real data of most logistics enterprises. For example, the vehicle types of 4.2 and $9.6 \mathrm{~m}$ are usually used in the road freight industry, and the tire numbers of 4.2 and $9.6 \mathrm{~m}$ vehicles are 6 and 8 , respectively. It can be seen from Table 1 that the profit of the carried commodity is shown as $v=\frac{V_{c}}{V_{v} F_{a}} \frac{C}{1-R_{p}} q-\frac{V_{c}}{V_{v} F_{e}} C$. Therefore, the transportation profit is related to many sensitive parameters, such as the anticipated load factor, the industrial average load factor, and the average profit rate of the industry of the road freight. In the following, we will consider a real example to show their sensibility.

Table 1. The description of some important variables for solving coalitions' utility function.

\begin{tabular}{|c|c|c|c|}
\hline Variable & Symbol & Unit & Necessary Illustrations \\
\hline Haul distance & K & $\mathrm{km}$ & No \\
\hline Maintenance and repair fee of vehicles & $F_{m}$ & yuan & 8000 for $4.2 \mathrm{~m} ; 14,000$ for $9.6 \mathrm{~m}$ \\
\hline Annual mileage & $K_{a}$ & $\mathrm{~km}$ & $K_{a}=26 \times 12 \times 10 \times 80=249,600$ \\
\hline Insurance fee of vehicles & $F_{i}$ & yuan & 10,000 for $4.2 \mathrm{~m} ; 17,000$ for $9.6 \mathrm{~m}$ \\
\hline Purchase fee of vehicles & $F_{p}$ & yuan & 120,000 for $4.2 \mathrm{~m} ; 260,000$ for $9.6 \mathrm{~m}$ \\
\hline Depreciation fee of vehicles & $F_{d}$ & yuan & The depreciation period is 8 years \\
\hline Driver's salary & $F_{S}$ & yuan & 8000 per month \\
\hline Diesel oil price & $P_{0}$ & yuan/L & 5.14 for $0 \#$ diesel oil \\
\hline Oil consumption fee & $C_{0}$ & $\mathrm{~L} / 100 \mathrm{~km}$ & 20 for $4.2 \mathrm{~m} ; 30$ for $9.6 \mathrm{~m}$ \\
\hline Highway toll fee & $T_{h}$ & yuan $/ \mathrm{km}$ & 1.54 for $4.2 \mathrm{~m} ; 1.65$ for $9.6 \mathrm{~m}$ \\
\hline Tire wear fee & $F_{t}$ & yuan & $\begin{array}{l}2100 \text { yuan per tyre. } \\
6 \text { tyres for } 4.2 \mathrm{~m} ; 8 \text { tyres for } 9.6 \mathrm{~m}\end{array}$ \\
\hline Vehicle interior volume & $V_{v}$ & $\mathrm{~m}^{3}$ & 15 for $4.2 \mathrm{~m}$; 60 for $9.6 \mathrm{~m}$ \\
\hline Commodity volume & $V_{c}$ & $\mathrm{~m}^{3}$ & No \\
\hline Anticipated load factor & $\widetilde{F}_{e}$ & No & No \\
\hline Industrial average load factor & $\tilde{F}_{a}$ & No & No \\
\hline Transport cost of the single trip & C & yuan & $C=F_{m}+F_{i}+F_{d}+F_{s}+C_{o}+T_{h}+F_{t}$ \\
\hline Actual transport cost of the carried commodity & $C_{a}$ & yuan & $C_{a}=\frac{V_{c}}{V_{v} F_{e}} C$ \\
\hline Average profit rate of the industry of the road freight & $R_{p}$ & No & Approximately $6 \%$ \\
\hline Industrial average non-tax quotation of the carried commodity & $P_{q}$ & yuan & $P_{q}=\frac{V_{c}}{V_{v} F_{a}} \frac{C}{1-R_{p}}$ \\
\hline Profit of the carried commodity & $v$ & yuan & $v=P_{q}-C_{a}$ \\
\hline
\end{tabular}

All of the three logistics enterprises need to carry goods by road transportation from City A to City B, the distance between which is $800 \mathrm{~km}$. Taking into account the fuzziness and uncertainty existing in the road freight industry, we used the intervals to express the anticipated load factor, $\widetilde{F}_{e}$, that is, $\widetilde{F}_{e}=\left[F_{L e}, F_{R e}\right]$. What is more, suppose we know in advance about the industrial average load factor, $\widetilde{F}_{a}$, which is also expressed as an interval, that is, $\widetilde{F}_{a}=\left[F_{L a}, F_{R a}\right]=[55 \%, 60 \%]$. The values of some important related parameters are shown as Table 2.

Table 2. The values of some important related parameters.

\begin{tabular}{cccc}
\hline Logistics & $\boldsymbol{V}_{\boldsymbol{c}}$ & $\tilde{\boldsymbol{F}}_{\boldsymbol{e}}$ & Planned Vehicle Type \\
\hline 1 & 4 & {$[68 \%, 71 \%]$} & $4.2 \mathrm{~m}$ \\
2 & 6 & {$[63 \%, 66 \%]$} & $4.2 \mathrm{~m}$ \\
3 & 30 & {$[65 \%, 70 \%]$} & $9.6 \mathrm{~m}$ \\
\hline
\end{tabular}


$C(i)(i=1,2,3)$ represents the transport cost of the single trip of the three logistics enterprises of 1,2 , and 3 , respectively. As for logistics enterprise 1 , it is obvious that

$$
\begin{gathered}
C(1)=F_{m}(1)+F_{i}(1)+F_{d}(1)+F_{s}(1)+C_{o}(1)+T_{h}(1)+F_{t}(1)=2508, \\
C_{R a}(1)=\frac{V_{c}(1)}{V_{v}(1) F_{L e}(1)} C(1)=983, P_{L q}(1)=\frac{V_{c}(1)}{V_{v}(1) F_{R a}(1)} \frac{C(1)}{1-R_{p}(1)}=1186, \\
v_{L}(1)=P_{L q}(1)-C_{R a}(1)=202 .
\end{gathered}
$$

Similarly, we can have $v_{L}(2)=186$ and $v_{L}(3)=366$.

In order to actively respond to the new changes in market competition, the three logistics enterprises of 1,2, and 3 decide to form possible coalitions to reduce cost and increase revenue.

The values of some of the important parameters of all of the possible coalitions are shown as Table 3.

Table 3. The values of some important related parameters of all of the possible coalitions.

\begin{tabular}{cccc}
\hline Coalition & $\boldsymbol{V}_{\boldsymbol{c}}$ & $\tilde{\boldsymbol{F}}_{\boldsymbol{e}}$ & Planned Vehicle \\
\hline$\{12\}$ & 10 & {$[76 \%, 80 \%]$} & $4.2 \mathrm{~m}$ \\
$\{13\}$ & 36 & {$[78 \%, 83 \%]$} & $9.6 \mathrm{~m}$ \\
$\{23\}$ & 38 & {$[85 \%, 90 \%]$} & $9.6 \mathrm{~m}$ \\
$\{123\}$ & 44 & {$[98 \%, 100 \%]$} & $9.6 \mathrm{~m}$ \\
\hline
\end{tabular}

$v(S)(S \subseteq N)$ represents the profit when all of the transport tasks assigned to the logistics enterprises in coalition $S$ are fulfilled. Take the coalition composed of logistics enterprises 1 and 2 (i.e., $v(12)$ ), for example; it is obvious that

$$
\begin{aligned}
& C(12)=2508, C_{R a}(12)=\frac{V_{c}(12)}{V_{v}(12) F_{L e}(12)} C(12)=2200, \\
& C(12)=2508, C_{R a}(12)=\frac{V_{c}(12)}{V_{v}(12) F_{L e}(12)} C(12)=2200,
\end{aligned}
$$

Similarly, we can have $v_{L}(13)=919, v_{L}(23)=1178$ and $v_{L}(123)=1721$.

So far, we have obtained the lower bounds of the coalition values (utility function) of all of the possible coalitions $v(S)(S \subseteq N)$, that is, $v_{L}(1)=202, v_{L}(2)=186, v_{L}(3)=366, v_{L}(12)=764$, $v_{L}(13)=919$, and $v_{L}(23)=1178, v_{L}(123)=1721$.

Similarly, we can obtain the upper bounds of the coalition values (utility function) of all of the possible coalitions $v(S)(S \subseteq N)$ as follows: $v_{R}(1)=351, v_{R}(2)=420, v_{R}(3)=788, v_{R}(12)=1144$, $v_{R}(13)=1365, v_{R}(23)=1626$, and $v_{R}(123)=2136$.

\subsection{Profit Allocation and Results Analysis}

If all of the three logistics enterprises form the grand coalition, $N$, according to Equation (18), we can easily obtain the lower bounds of the interval-valued profits of the three logistics enterprises of 1,2 , and 3, which are shown as follows:

$$
\begin{aligned}
& x_{L 1}^{*}=\frac{v_{L}(N)}{5}+\frac{1}{5 \times 2^{n-2}}\left(5 a_{L 1}(v)-\sum_{j \in N} a_{L j}(v)\right)=\frac{200}{5}+\frac{1}{5 \times 8}(5 \times 1075-7485)=437, \\
& x_{L 2}^{*}=\frac{v_{L}(N)}{5}+\frac{1}{5 \times 2^{n-2}}\left(5 a_{L 2}(v)-\sum_{j \in N} a_{L j}(v)\right)=\frac{200}{5}+\frac{1}{5 \times 8}(5 \times 1295-7485)=558,
\end{aligned}
$$




$$
x_{L 3}^{*}=\frac{v_{L}(N)}{5}+\frac{1}{5 \times 2^{n-2}}\left(5 a_{L 3}(v)-\sum_{j \in N} a_{L j}(v)\right)=\frac{200}{5}+\frac{1}{5 \times 8}(5 \times 1770-7485)=726 .
$$

In a similar way, according to Equation (19), we can easily obtain the upper bounds of the interval-valued profits of the three logistics enterprises of 1,2 , and 3 , which are shown as follows:

$$
\begin{aligned}
& x_{R 1}^{*}=\frac{v_{R}(N)}{5}+\frac{1}{5 \times 2^{n-2}}\left(5 a_{R 1}(v)-\sum_{j \in N} a_{R j}(v)\right)=\frac{200}{5}+\frac{1}{5 \times 8}(5 \times 1075-7485)=504, \\
& x_{R 2}^{*}=\frac{v_{R}(N)}{5}+\frac{1}{5 \times 2^{n-2}}\left(5 a_{R 2}(v)-\sum_{j \in N} a_{R j}(v)\right)=\frac{200}{5}+\frac{1}{5 \times 8}(5 \times 1075-7485)=669 \\
& x_{R 3}^{*}=\frac{v_{R}(N)}{5}+\frac{1}{5 \times 2^{n-2}}\left(5 a_{R 3}(v)-\sum_{j \in N} a_{R j}(v)\right)=\frac{200}{5}+\frac{1}{5 \times 8}(5 \times 1075-7485)=963 .
\end{aligned}
$$

Therefore, the interval-valued profits of the three logistics enterprises of 1,2 , and 3, allocated from the grand coalition, $N$, can be shown as $\bar{x}_{1}^{*}=\left[x_{L 1}^{*}, x_{R 1}^{*}\right]=[437,504], \bar{x}_{2}^{*}=\left[x_{L 2}^{*}, x_{R 2}^{*}\right]=[558,669]$, and $\bar{x}_{3}^{*}=\left[x_{L 3}^{*}, x_{R 3}^{*}\right]=[726,963]$, respectively. Furthermore, the lower limit and the upper limit of the sum of all of the three logistics enterprises' allocation results is 1721 and 2136, respectively. In other words, the payoff vector $\bar{x}^{*}=\left[\bar{x}_{1}^{*}, \bar{x}_{2}^{*}, \bar{x}_{3}^{*}\right]$ obtained based on the allocation method proposed in this paper (i.e., interval-valued least square excess solution) is an imputation and efficient.

Take logistics enterprise 1 for example. When doing business alone, the minimum profit is 202 (yuan) and the maximum profit is 351 (yuan). However, once it joins the grand cooperative coalition, $N$, the minimum profit allocated will increase to 437 (yuan) and the maximum profit allocated will increase to 504 (yuan). As for logistics enterprises 2 and 3, the change tendency of the profit allocated from the grand cooperative coalition, $N$, are similar to that of logistics enterprise 1.

For any logistics enterprise, it will gain more transportation profit if it joins the grand coalition, $N$. That is to say, if all of the logistics enterprises form a coalition to complete transportation tasks, each logistics enterprise can maximize its own interest. As a consequence, the grand coalition, $N$, is strong and each logistics enterprise has great enthusiasm for participation.

In order to demonstrate the superiority of the proposed method in this paper, we obtained the allocation results of the coalition profits according to the interval Shapley-like value $\boldsymbol{\phi}^{*}(v)$ (Han, Sun, $\mathrm{Xu}, 2012)$. As for logistics enterprise 1, we have

$$
\begin{aligned}
& \phi_{1}^{*}(v)=\sum_{S \subseteq N \backslash i} \frac{|S| !(|N|-|S|-1) !}{|N| !}(v(S \cup\{i\})-v(S)) \\
& =\frac{1}{3}[v(1)-v(\varnothing)+v(12)-v(2)+v(13)-v(3)+v(123)-v(23)]=[178,763]
\end{aligned}
$$

In the similar way, the final allocation results of logistics enterprise 1 and 2 can be obtained as $\phi_{2}^{*}(v)=[315,913]$ and $\phi_{3}^{*}(v)=[535,1154]$, respectively. Observing carefully the allocation results via the interval Shapley-like value, it is not difficult to find that the sum of the allocation results of all the three logistics enterprises is not equal to the total profit from cooperation. The lower limit of the sum of all of the three logistics enterprises' allocation results is 1028, which is less than 1721 . However, the upper limit of the sum of all of the three logistics enterprises' allocation results is 2930, which is more than 2136. That is to say, the interval Shapley-like value is not efficient. Furthermore, the interval Shapley-like value uses the subtraction of intervals many times, which will directly result in the amplification of fuzzy uncertainty.

\section{Conclusions}

Based on the above analysis, the proposed interval-valued least square excess solution has many advantages, as follows: 
(1) The proposed interval-valued least square excess solution is a new and intuitive method for solving intervalvalued fuzzy cooperative games. According to Equations (18) and (19), the interval-valued least square excess solution can be obtained just through a simple calculation.

(2) The magnification of the fuzziness and uncertainty will be the result of the subtraction of intervals. In order to reduce the amplification of the fuzziness and uncertainty during the process of calculation, we use the square distance to define the difference between two intervals, instead of the interval subtraction, and propose the corresponding mathematical programming model. According to the existing research, most of the proposed methods [2,4] inevitably use the interval subtraction operation [8] and may not effectively overcome this disadvantage.

(3) Players may obtain negative payoffs according to some of the existing models and methods [5], which are not rational. However, the interval-valued least square excess solution is always positive, as long as all of the coalitions' values are positive.

(4) The interval-valued least square excess solution can be considered as the expansion of the least square prenucleolus for crisp cooperative games. It can be verified that the interval-valued least square excess solution satisfies some important and excellent properties such as uniqueness, additivity, and anonymity, in the same way as the least square prenucleolus for crisp cooperative games.

The interval-valued least square excess solution proposed in this paper is the generalization of the least square prenucleolus for classical cooperative games [15]. Under the fuzzy environment, the coalition values can be expressed by triangular fuzzy numbers [17-19], triangular intuitionistic fuzzy numbers [20], Pythagorean fuzzy numbers [21,22], and some other types of fuzzy numbers [23-25]. Therefore, the fuzzy cooperative games with coalition values expressed by other fuzzy numbers, such as TFNs and TIFNs, will be important research hotspots in the future.

Author Contributions: W.-J.Z. conceived, designed, and wrote the manuscript; J.-C.L. collected the data and revised the manuscript. Both of the authors have read and approved the final manuscript.

Funding: This research was funded by the Social Science Planning Program of Fujian Province of China (no. FJ2018B014), the Special Foundation Program for Science and Technology Innovation of Fujian Agriculture and Forestry University of China (no. CXZX2018030) and the National Natural Science Foundation of China (no. 71572040). The APC was funded by the Fujian Agriculture and Forestry University of China.

Conflicts of Interest: The authors declare no conflict of interest.

\section{References}

1. Branzei, R.; Branzei, O.; Alparslan Gök, S.Z.; Tijs, S. Cooperative interval games: A survey. Cent. Eur. J. Oper. Res. 2010, 18, 397-411. [CrossRef]

2. Alparslan Gök, S.Z.; Branzei, R.; Tijs, S. The interval Shapley value: An axiomatization. Cent. Eur. J. Oper. Res. 2010, 18, 131-140. [CrossRef]

3. Mallozzi, L.; Scalzo, V.; Tijs, S. Fuzzy interval cooperative games. Fuzzy Sets Syst. 2011, 165, 98-105. [CrossRef]

4. Alparslan Gök, S.Z.; Palancı, O.; Olgun, M.O. Cooperative interval games: Mountain situations with interval data. J. Comput. Appl. Math. 2014, 259, 622-632. [CrossRef]

5. Han, W.B.; Sun, H.; Xu, G.J. A new approach of cooperative interval games: The interval core and Shapley value revisited. Oper. Res. Lett. 2012, 40, 462-468. [CrossRef]

6. Li, D.F. Fuzzy Multiobjective Many-Person Decision Makings and Games; National Defense Industry Press: Beijing, China, 2003. (In Chinese)

7. Branzei, R.; Dimitrov, D.; Tijs, S. Shapley-like values for interval bankruptcy games. Econ. Bull. 2003, 3, 1-8.

8. Moore, R. Methods and Applications of Interval Analysis; SIAM Studies in Applied Mathematics; Society for Industrial Mathematics: Philadelphia, PA, USA, 1979.

9. Kimms, A.; Drechsel, J. Cost sharing under uncertainty: An algorithmic approach to cooperative interval-type games. Bus. Res. 2009, 2, 206-213. [CrossRef]

10. Alparslan Gök, S.Z.; Branzei, O.; Branzei, R.; Tijs, S. Set-valued solution concepts using interval-type payoffs for interval games. J. Math. Econ. 2011, 47, 621-626. [CrossRef] 
11. Branzei, R.; Alparslan Gök, S.Z.; Branzei, O. Cooperation games under interval uncertainty: On the convexity of the interval undominated cores. Cent. Eur. J. Oper. Res. 2011, 19, 523-532. [CrossRef]

12. Alparslan Gök, S.Z.; Miquel, S.; Tijs, S. Cooperation under interval uncertainty. Math. Methods Oper. Res. 2009, 69, 99-109. [CrossRef]

13. Li, D.F. Linear programming approach to solve interval-type matrix games. Omega Int. J. Manag. Sci. 2011, 39, 655-666. [CrossRef]

14. Li, D.F. Models and Methods of Interval-Type Cooperative Games in Economic Management; Springer: Cham, Switzerland, 2016.

15. Ruiz, L.M.; Valenciano, F.; Zarzuelo, J.M. The least square prenucleolus and the least square nucleolus. Two values for TU games based on the excess vector. Int. J. Game Theory 1996, 25, 113-134. [CrossRef]

16. Schmeidler, D. The Nucleolus of a Characteristic Function Game. SIAM J. Appl. Math. 1969, 17, 1163-1170. [CrossRef]

17. Li, D.F. A fast approach to compute fuzzy values of matrix games with payoffs of triangular fuzzy numbers. Eur. J. Oper. Res. 2012, 223, 421-429. [CrossRef]

18. Chandra, S.; Aggarwal, A. On solving matrix games with pay-offs of triangular fuzzy numbers: Certain observations and generalizations. Eur. J. Oper. Res. 2015, 246, 575-581. [CrossRef]

19. Li, D.F. Linear Programming Models and Methods of Matrix Games with Payoffs of Triangular Fuzzy Numbers; Springer: Berlin/Heidelberg, Germany, 2016.

20. Verma, T.; Kumar, A.; Appadoo, S.S. Modified difference-index based ranking bilinear programming approach to solving bimatrix games with payoffs of trapezoidal intuitionistic fuzzy numbers. J. Intell. Fuzzy Syst. 2015, 29, 1607-1618. [CrossRef]

21. Garg, H. New Logarithmic operational laws and their aggregation operators for Pythagorean fuzzy set and their applications. Int. J. Intell. Syst. 2019, 34, 82-106. [CrossRef]

22. Garg, H. New exponential operational laws and their aggregation operators for interval-valued Pythagorean fuzzy multicriteria decision-making. Int. J. Intell. Syst. 2018, 33, 653-683. [CrossRef]

23. Garg, H. Linguistic Pythagorean fuzzy sets and its applications in multiattribute decision-making process. Int. J. Intell. Syst. 2018, 33, 1234-1263. [CrossRef]

24. Grzegorzewski, P. On Separability of Fuzzy Relations. Int. J. Fuzzy Log. Intell. Syst. 2017, 17, 137-144. [CrossRef]

25. Jang, L.C.; Lee, J.G.; Kim, H.M. On Jensen-Type and Hölder-Type Inequality for Interval-Valued Choquet Integrals. Int. J. Fuzzy Log. Intell. Syst. 2018, 18, 97-102. [CrossRef] 